\title{
Correction to: A new topological descriptor for water network structure
}

Lee Steinberg ${ }^{1}$ (D) John Russo ${ }^{2}$ (i) and Jeremy Frey ${ }^{1 *}$ (])

\section{Correction to: J Cheminform (2019) 11:48} https://doi.org/10.1186/s13321-019-0369-0

It was highlighted that the original article [1] was missing Additional files 2 and 3.

This Correction article includes the missing Additional files 2 and 3 :

- Supporting Information.docx

- Details as to simulations

- Utilities.zip

- Python scripts for running analysis

\section{Additional files}

Additional file 2. Simulations details.

Additional file 3. Python scripts for running analysis.

\section{Author details}

${ }^{1}$ School of Chemistry, University of Southampton, Southampton SO17 1BJ,

UK. ${ }^{2}$ School of Mathematics, University of Bristol, Bristol, UK.

The original article can be found online at https://doi.org/10.1186/s1332 1-019-0369-0.

Published online: 07 August 2019
Reference

1. Steinberg L, Russo J, Frey J et al (2019) A new topological descriptor for water network structure. J Cheminform 11:48. https://doi.org/10.1186/ s13321-019-0369-0

\section{Publisher's Note}

Springer Nature remains neutral with regard to jurisdictional claims in published maps and institutional affiliations.

*Correspondence: J.G.Frey@soton.ac.uk

${ }^{1}$ School of Chemistry, University of Southampton, Southampton $\mathrm{SO} 17$

1BJ, UK

Full list of author information is available at the end of the article 